\title{
Editorial:
}

\section{Building Canadian Gerontology: A Springboard for International Recognition?}

A scientific field becomes part of the social fabric through institutions: university training and research units, scientific and educational associations, learned periodicals and research grant agencies. The crystallization of these institutions is the result of complex interactions by committed and far-seeing participants; they are able to access resources and mobilize them in order to continue expanding their field, generate knowledge and train practitioners. Gerontology in Canada so far has benefited from the presence and dedication of visionaries who have spent 25 years establishing scientific and professional institutions, as well as setting up research and training that are in many respects outstanding. In Quebec, the field took longer to get started and has been less focussed on research centres or groups. Can gerontology in Canada and Quebec keep up this momentum? What is the outlook for the future?

Canadian gerontology developed during a relatively favourable period for expansion. During the 1970s and until the late 1980s, the neo-liberal views current today were just taking shape, but major social programs were being set up, implemented and consolidated. Universal health care insurance in particular seemed to be developing a valuable, if modest, offshoot in longterm care, following the adoption in 1977 of The Established Programs Financing (EPF) for federal transfer payments to the provinces, the gradual introduction of home care, and a change in the role of institutionalized care for the elderly. Finally, despite all the claims about the marginalizing of old people, attempts at de-indexing federal old age pensions met with resistance from seniors' organizations, backed by other age groups.

This was the social context in which the Canadian Association on Gerontology was established: the Social Sciences and Humanities Research Council set up its funding program to provide infrastructures for university research in gerontology; the Canadian Journal on Aging was founded. The federal government created various programs, directorates and advisory groups on the elderly: a few examples, not necessarily in chronological order, were the National Advisory Council on Aging, the "New Horizons" program, and the Seniors Independence Research Program (SIRP). Health Canada funded research into the autonomy of seniors and Alzheimer's disease, while Statistics Canada undertook research into the functional problems of the elderly. Some general social surveys were partly devoted to aspects of aging: networks and social support, for example. Other major projects were set up and obtained funding, illustrating the dynamism of Canadian gerontology. To mention just one example, the only social sciences project funded 
as part of the first wave of centres of excellence was CARNET: The Canadian Aging Research Network, a research program involving a social gerontology research team.

Times have changed. Old age income security is no longer a universal federal program. Major social programs are no longer being created. Political rhetoric is now dominated by the deficit and the reduced role of the government. In Canada, there is probably only one social program whose principles are sacrosanct: universal health insurance. Quebec has even extended it to cover prescription medication, with a mixed private and public program that guarantees minimum coverage for all Quebeckers. But this program originated as much in the need to provide access to costly drugs formerly distributed during hospitalization, as in the Quebec government's desire to recover $\$ 200$ million annually compared with the previous drug insurance plan, which only covered the elderly and citizens on welfare. Paradoxically, the program was made universal so that it would cost the government less money!

While the social, political and economic climate was changing, the structure of gerontology research set up during the 1980s was being eroded. The only French-speaking university research centre, at the Universite de Moncton, almost closed down; it continues to function, but at a reduced level. In English Canada, gerontology research centres have been closed down or their mandates have been extended to broader issues; the active survival of the most productive centres seems to be related to the presence of dynamic personalities with clout, rather than necessarily to a strong tradition of research based on ongoing work.

We do not seek to be alarmist. Gerontology researchers do not necessarily require dedicated research centres in order to be productive. From my experience as editor of the Canadian Journal on Aging, I know that, from 1990 to 1996, the number of manuscripts submitted and published more than doubled, although this was a period when difficult times had been foreseen and, indeed, came to pass. However, during the last year of my term, the number of papers submitted suddenly dropped. Does this signal the beginning of a long-term reduction or was it just a temporary setback? And if it was the first sign that the number of papers submitted is shrinking, is this limited to the Canadian Journal on Aging? Or does it indicate that less scientific writing is going on in the gerontology field? Perhaps in all Canadian social science periodicals?

It would be useful to know what has happened. If it is only the $C J A$ to which fewer articles are being submitted, this may indicate that a particular Canadian scientific review has become less popular among our researchers. The outstanding loyalty of gerontology researchers to the $C J A$ would appear to be diminshing in favour of foreign periodicals. In other words, gerontology researchers are beginning to behave like their colleagues in other fields. The $C J A$, like many Canadian learned periodicals, would seem to be condemned to a purely local role even though, during its early years, it seemed set to penetrate the international market. 
Shrinking scientific production in gerontology would be even more worrying. We would need to determine whether the same is happening in other disciplines. The sparse budgets of public bodies that fund research and the fostering of links between university research and the private sector or public institutions are two current government policies that may be responsible for reducing the amount of scientific information being submitted for publication. ${ }^{1}$

Another factor is of concern for the future of gerontology. It is not only funds at major federal research funding bodies - SSHRC, MRC, NHRDP that are scarcer than before; organizations that formerly played a vital role in developing research on the elderly, such as the NHRDP, are changing their focus from applied research to directed research. Gerontology has always been concerned with the practical: it has never been overly theoretical. To claim that gerontology researchers neglected the practical problems of aging is therefore wrong. They were simply defining the areas of research that appeared most interesting and promising. In this way, Canadian research made a name for itself on the international scene, thanks to the work at the University of British Columbia and the University of Manitoba on the use of health care services by the elderly; the work on social support and the family at the University of Victoria and the University of Guelph; the study of elderly workers by the University of Toronto. Other researchers in Quebec, New Brunswick, Newfoundland and Alberta were also noted for their work in the psychology and sociology of aging. The list goes on, and I apologize to all those I have failed to mention. But despite this remarkable amount of applied scientific work, funding bodies today claim to be directing research toward "fruitful" themes.

This shift toward selective funding of research topics, chosen by political and bureaucratic decision-makers, though involving prior consultations with the community, has not taken into consideration the recent history of Canadian gerontology research work, its deeply-rooted basis in applied research, and the commitment of researchers to the most problematic issues of aging.

The recent change in orientation among certain research funding organizations in favour of directed research has hardly ever been accompanied by adequate resources; rather, it has simply resulted in fewer funds being allocated to research. It is true that the experience of the SIRP could be said to prove the contrary. However, it is most unlikely to be repeated; also, since SIRP projects last only three years, researchers are thus limited to crosssectional research or analysis of secondary data.

The other major problem of gerontological research is that the research funding process makes it extremely difficult to conduct innovative, largescale or risky projects or those that stray from well-trodden paths. There is thus a major danger that Canadian research in gerontology will become marginalized. Let us examine one instance. Linda George (1996) in the fourth edition of the Handbook of Aging and the Social Sciences, claims that, with few exceptions, we cannot expect much from cross-sectional 
approaches to research into social support for the elderly; we must therefore conduct longitudinal research. Although this claim may be somewhat exaggerated, its message is worth heeding: to the extent that statements by major figures in the research world are eventually shared by lesser figures, and that both apply them to the review of journal articles, these become the norms that decide what should be published or rejected.

In other words, if Professor George's opinion becomes widely accepted, it will become increasingly difficult to publish research work on social support unless it is longitudinal. Indeed, it is true that longitudinal studies provide better answers to certain research questions than do cross-sectional studies. However, the funding, organization and conduct of longitudinal research cannot be run and managed in the same way as are cross-sectional studies limited in time. Canadian and Quebec researchers have been trained to plan, draft and execute short-term projects funded for two or three years. In doing so, they have simply been complying with the funding cycles imposed by research funding bodies.

Gerontology research in the Canadian community can achieve modest but solid progress using the resources available to researchers in all disciplines. There are, and probably always will be, intelligent, enterprising researchers who gather around them small teams whose publications are mainly destined for American and international scientific journals. These individuals will also be able to act as consultants to federal, provincial, regional or local agencies. Looking at this from another angle, gerontology research can be based in Canadian institutions in order to contribute to the development of international gerontology and at the same time help to define and address the issues of population aging. This would require active input by the Canadian Association on Gerontology (CAG) in the public debate on aging, based on research findings; top researchers from at home and abroad would have to attend the annual conference of the CAG; and the Canadian Journal on Aging would have to be used and promoted as the normal venue for communicating the results of research work. This also requires a new approach to research, one that rewards innovation, ambition and risk-taking.

There are a number of ways to foster innovation, and promote the quality and continuity of research work. That is not the issue of this editorial. However, it is important that adequate means are used, and these are only made available for priority objectives that enjoy public acclaim. I have the feeling, and I hope I am wrong, that aging is no longer a priority for governments or even for intellectuals in the health care field. The report of the National Forum on Health (1997) defines one age group as a priority: children. This choice is valid and understandable. The Forum's only priority area relating to aging is home care services. This is a curious and narrow priority because it is not really part of a broader discussion about the overall organization of care and services for the elderly. A change can be sensed in society's attitude to seniors. Once the concern of society, albeit in a paternalistic fashion, seniors today are regarded with comparative indifference. 
Comparative, because even if health and welfare policy priorities now focus on children and adolescents, services and financial support for the elderly will continue to be "administrative" concerns. Research will be needed to address the concrete problems of organizing public programs for the elderly; but this research will have no future unless it succeeds in asking the right questions and using its quality and strength to obtain the resources it needs to develop its own research programs.

\section{Note}

1 Another explanation for the falling number of manuscripts submitted is more workaday: the large number of articles submitted for publication may have resulted in longer publication delays and researchers avoiding the $C J A$. Although this may be partly true, I do not regard it as an entirely satisfactory explanation.

\section{References}

George, L. (1996). Social Factors and Illness. In R.H. Binstock \& L. George (Eds.), Handbook of Aging and the Social Sciences, (4th ed.) (pp. 229-248). San Diego: Academic Press Inc.

National Forum on Health. (1997). Canada health action: building on the legacy. Final report of the National Forum on Aging. Ottawa: Public Works and Government Services Canada. 